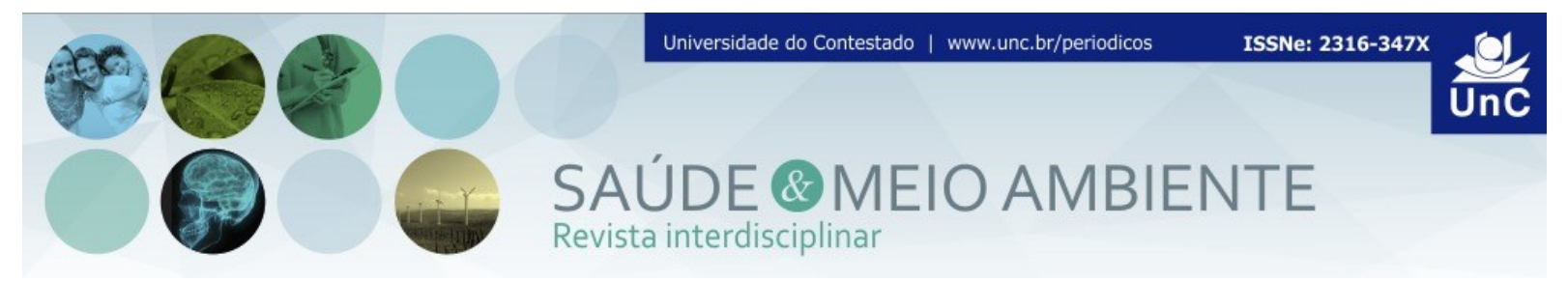

\title{
CONCEPÇÕES E PRÁTICAS DA EDUCAÇÃO AMBIENTAL
}

RESUMO

Tiago Kamiensky Lopes ${ }^{1}$

Solange Reiguel Vieira ${ }^{2}$

Viviane Maneira ${ }^{3}$

Vivian Cristine de Lima Corrêa ${ }^{4}$

Genésio Roberto Camargo ${ }^{5}$

Atualmente a relação entre meio ambiente e educação têm assumido um papel desafiador. A Educação Ambiental é considerada uma dimensão da educação, que trata da relação entre sociedade e meio ambiente, essencial para a formação dos sujeitos. Assim, a disciplina de Geografia por tratar dessas questões que se materializam no espaço geográfico contribui para que a Educação Ambiental seja efetivada de forma mais eficaz e contextualizada dentro das instituições de ensino. Nesse sentido, faz-se necessário identificar a maneira como os conteúdos relacionados à Educação Ambiental são trabalhados nos ambientes escolares. $O$ artigo procura identificar as concepções e práticas de Educação Ambiental bem como analisar as dificuldades encontradas no seu desenvolvimento no cotidiano escolar e comunidade. O campo empírico da pesquisa foram duas escolas públicas estaduais localizadas no município de Rio Negro-PR, com a participação de alunos do terceiro ano do ensino médio e professores. Este trabalho possui abordagem metodológica qualitativa. Para a coleta de dados foram realizadas pesquisa documental, bibliográfica, exploratória e pesquisa de campo com aplicação de questionários e entrevistas. Os dados coletados foram analisados com enfoque qualitativo, por meio da técnica de análise de conteúdo. Os resultados evidenciaram que existem lacunas entre o ensino e a Educação Ambiental. O processo da inserção da Educação Ambiental necessita de uma elaboração metodológica inovadora que precisa ser construída passo a passo com a comunidade escolar, considerando a realidade vivenciada na sociedade atual. A Educação Ambiental tem sido um elemento essencial para se repensar as práticas e teorias que fundamentam as ações educativas de maneira interdisciplinar, seja nos ambientes formais ou informais da educação, constituindo assim verdadeiras comunidades de aprendizagem.

Palavras-chave: Ensino de Geografia. Interdisciplinaridade. Meio Ambiente.

\footnotetext{
${ }^{1}$ Licenciado em Geografia, Universidade Estadual de Ponta Grossa (UEPG).- Bacharelado em Ciências Biológicas pela Universidade do Contestado. Santa Catarina. Brasil. E-mail: tiagobiogeo@gmail.com

2Licenciada em Geografia. Mestra em Ciência e Tecnologia Ambiental, Universidade Tecnológica Federal do Paraná (UTFPR). Paraná. Brasil. E-mail: solgeografia@gmail.com

${ }^{3}$ Licenciada em Geografia, Universidade Estadual de Ponta Grossa (UEPG). Paraná. Brasil. E-mail: vivianemaneira@bol.com.br

${ }^{4}$ Licenciada em Geografia, Universidade Estadual de Ponta Grossa (UEPG). Paraná. Brasil. Email:Viviancorrea87@hotmail.com

${ }^{5}$ Licenciado em Geografia, Universidade Estadual de Ponta Grossa (UEPG). Paraná. Brasil. E-mail: gen.harima@hotmail.com
} 


\title{
ENVIRONMENTAL EDUCATION CONCEPTIONS AND PRACTICES
}

\begin{abstract}
Nowadays the relationship between environment and education has assumed a challenging role. Environmental Education is considered a dimension of education which deals with the relationship between society and the environment, essential for the formation of subjects. Thus, the Geography subject for dealing with these issues that materialize in the geographic space contributes to Environmental Education being effected more effectively and contextualized within the educational institutions. In this sense, it is necessary to identify the way in which the contents related to Environmental Education are worked in the school environments. The article seeks to identify the concepts and practices of Environmental Education as well as to analyze the difficulties found in its development in the daily school and community. The empirical field of the research were two state public schools located in Rio Negro-PR city, with the participation of the third year high school students and teachers. This work has a qualitative methodological approach. For the collection of data were carried out documentary, bibliographic, exploratory research and field research with application of questionnaires and interviews. The collected data were analyzed with a qualitative approach, through the technique of content analysis. The results showed that there are gaps between teaching and Environmental Education. The process of putting Environmental Education requires a new methodological elaboration that needs to be built step by step with the school community, considering the reality experienced in today's society. Environmental Education has been an essential element to rethink the practices and theories that underpin educational actions in an interdisciplinary way, as well as in the formal or informal environments of education, therefore forming true learning communities.
\end{abstract}

Key words: Geography teaching. Interdisciplinarity. Environment.

\section{INTRODUÇÃO}

Atualmente a relação entre meio ambiente e educação têm assumido um papel desafiador a cada dia, frente às mudanças e desafios contemporâneos. As instituições de ensino têm o dever de promover a Educação Ambiental, de uma forma integrada, contínua e permanente, contemplando todos os níveis e modalidades de ensino, como previsto na legislação nacional e estadual.

Esses documentos oficiais brasileiros orientam e apoiam projetos participativos e integrados sobre a Educação Ambiental que devem ser desenvolvidos de maneira contempladora onde ofereça mais do que informações, aliando o conhecimento com a prática, possibilitando atravessar os muros das escolas, num envolvimento com a comunidade, sendo os pilares para construção do 
pensamento crítico sobre os fatos e fenômenos que acontecem no dia a dia da sociedade (BRASIL, 2012).

É de suma importância obter conhecimento referente às atividades desempenhadas pelas escolas, pois é através delas que temos a oportunidade de despertarmos a sensibilização dos nossos alunos para ações que deem conta de minimizar os impactos causados pelas atividades humanas sobre o meio ambiente. Assim, a maneira mais propícia de alcançarmos bons resultados é através da Educação Ambiental, pois ela é a chave desencadeadora para a busca pela solução destes problemas.

O conceito contemporâneo mostra que a Educação Ambiental assume um papel mais realista, com base na tentativa de estabelecer o equilíbrio entre as atividades humanas e o ambiente. Diante deste pensamento, a Educação Ambiental assume um importante papel para a educação na busca pelo desenvolvimento sustentável formando cidadãos sensibilizados pelas causas ambientais, instruídos por programas educativos. Para Sauvé (2005, p. 317):

\begin{abstract}
A educação ambiental não é, portanto, uma 'forma' de educação (uma 'educação para') entre inúmeras outras; não é simples mente uma 'ferramenta' para a resolução de problemas ou de gestão do meio ambiente. Trata-se de uma dimensão essencial da educação fundamental que diz respeito a uma esfera de interações que está na base do desenvolvimento pessoal e social: a da relação com o meio em que vivemos, com essa 'casa de vida" compartilhada. A educação ambiental visa a induzir dinâmicas sociais, de início na comunidade local e, posteriormente, em redes mais amplas de solidariedade, promovendo a abordagem colaborativa e crítica das realidades socioambientais e uma compreensão autônoma e criativa dos problemas que se apresentam e das soluções possíveis para eles.
\end{abstract}

Atualmente, a educação passa por uma profunda mudança, pautada na interdisciplinaridade, na gênese de um ensino permanente, capaz de moldar o mundo, criando valores de uma sociedade sustentável no equilíbrio das relações econômicas, sociais, culturais e no respeito com o meio ambiente.

Neste contexto, a disciplina de Geografia possui um grande potencial, pois é a que mais aborda a relação homem e meio ambiente, e esta relação não é um fato inédito. Ao analisarmos a história da Geografia, percebemos que hoje, esta relação é discutida com mais intensidade e importância, se comparados há algumas décadas, e muitos dos conteúdos relacionados ao meio ambiente, são abordados pelo olhar da Geografia, que dialoga com outras áreas do conhecimento.

É evidente que o ensino da Geografia possibilita um aprofundamento de estudos nas relações do homem com o meio ambiente. Dentro deste contexto, para efetivarmos a Educação Ambiental não podemos separá-la da educação geográfica. Muito pelo contrário, observamos a afinidade e as interrelações existentes entre ambas, sendo necessário o entendimento desta relação, de forma não fragmentada entre o espaço físico e o humano como conteúdos distintos, mas de uma maneira 
onde exista uma junção dos fenômenos que compõem o espaço geográfico na sua totalidade.

A Geografia é a área do conhecimento responsável por apresentar uma visão de mundo diferenciada dos outros ramos do conhecimento, assim ela prepara um olhar acerca dos fenômenos intrinsecamente ligados ao espaço. Desta maneira, a Ciência Geográfica tem a função de mediar às relações entre a sociedade e o meio ambiente tornando um conteúdo de forte expressão.

De acordo com Oliveira (2011, p.30):

A Geografia tem como propósito a formulação de uma percepção mais clara da relação que existe entre a sociedade e as modificações que esta causa ao meio ambiente. Posto desta forma, a Educação Ambiental pode se utilizar desta percepção para melhor formar os autores sociais. Além disso, a Geografia, como ciência, possui um conjunto de formulações teóricas que servirão para formar conceitos que apreendam os complexos processos sociais, e os riscos ambientais que se intensificam.

Conciliar a Geografia e a Educação Ambiental é de suma importância para a sensibilização dos indivíduos sobre suas concepções e práticas na preservação ambiental. Compreender os fenômenos que nos cercam e conhecer os cuidados necessários para o bom funcionamento do sistema mundo é um dos objetivos do estudo da Geografia, pois através dela as relações sociais são trabalhadas num contexto mais abrangente de entendimento da espacialidade e prepara os novos rumos do espaço social. Escreve Silva (2009, p.11):

\footnotetext{
Apesar de a Educação Ambiental ter o princípio pedagógico da interdisciplinaridade, na prática isto não ocorre, ela está restrita a algumas ciências: Geografia, Biologia, Química, Física, História, etc. Cada uma destas disciplinas escolares incorporou o discurso ambiental, porém com enfoques diferentes. Dentre estas disciplinas é importante destacar o enfoque dado às questões ambientais pela Geografia.
}

Enfim, existe uma necessidade de aprofundar os estudos metodológicos e práticos acerca da inserção da Educação Ambiental no ensino da Geografia, e uma das formas de isso acontecer é conhecendo as possibilidades de concepções e práticas utilizadas por outras áreas do ensino e aprendizagem.

O trabalho procurou identificar as concepções e práticas de Educação Ambiental, bem como analisar as dificuldades encontradas no seu desenvolvimento no cotidiano escolar e na comunidade.

\section{MATERIAIS E MÉTODOS}

O campo empírico da pesquisa é o ambiente escolar, especificamente duas instituições de ensino da rede pública estadual, escolhidas de forma intencional, por se tratarem de diferentes modalidades de ensino e propostas pedagógicas, sendo 
umas delas enquadrada no regime de ensino regular formal e outra no ensino técnico profissionalizante, voltado às práticas agropecuárias. Entretanto, essas escolas não se diferenciam apenas pelo ensino, mas também pelas suas localizações geográficas, sendo que uma está situada na área urbana e outra na área rural da cidade de Rio Negro-PR.

Os sujeitos participantes da pesquisa foram alunos do terceiro ano do ensino médio e professores de diferentes disciplinas. A opção pela escolha das referidas turmas deve-se ao fato dos mesmos terem um período maior de estudo dentro das instituições. Já, a escolha de professores aleatórios foi realizada para a investigação de como ocorre o processo da interdisciplinaridade.

O estudo foi desenvolvido com enfoque metodológico qualitativo. Para a coleta de dados foram utilizadas a pesquisa documental, bibliográfica, exploratória e pesquisa de campo através da aplicação de questionários e entrevistas.

A pesquisa documental e bibliográfica foi utilizada afim de obter informações complementares ao tema e embasamento teórico da pesquisa exploratória sobre as dificuldades dos professores no desenvolvimento dos conteúdos e projetos relacionados à Educação Ambiental, bem como na avaliação do conhecimento dos alunos sobre o assunto, buscando meios de incentivos junto aos alunos e professores e inter-relacionar a disciplina de Geografia com a Educação Ambiental. Assim, foram utilizados documentos oficiais e trabalhos de autores renomados na temática ambiental e geográfica.A pesquisa de campo foi realizada através da aplicação de questionários com uma parcela de alunos e entrevistas com os professores, buscando a obtenção de respostas contundentes sobre a importância e o enfoque que as instituições pesquisadas tratam a temática da Educação Ambiental, bem como uma visão breve do conhecimento dos alunos sobre meio ambiente e as relações existentes entre homem e natureza no contexto dos problemas ambientais. Esta técnica foi utilizada para o desenvolvimento da pesquisa nas escolas, a fim de obter dados para investigar as concepções e práticas da Educação ambiental no ambiente escolar.

As entrevistas aplicadas aos professores, contaram com as seguintes participações: três (3) de cada instituição de ensino, sendo um (1) professor de Geografia de cada escola e dois (2) professores das demais disciplinas, sendo elas, Educação Física, Filosofia, Inglês e Produção Vegetal. Tais entrevistas foram constituídas de sete (7) perguntas abertas previamente elaboradas pelos pesquisadores.

Os questionários direcionados aos alunos apresentaram dez (10) perguntas, sendo sete (7) questões de múltipla escolha e três (3) questões objetivas, respondidas por 42 alunos, sendo destes, sendo vinte e oito (28) alunos da primeira escola e catorze (14) alunos da segunda escola.

Os dados coletados foram tabulados e analisados com enfoque qualitativo, por meio da técnica de análise de conteúdo (BARDIN, 2011).

Os resultados das entrevistas dos professores foram classificados e organizados de forma sistemática, agrupando-se os elementos em categorias de 
modo a facilitar a análise, assim como as respostas em comum. Desse modo, as respostas das entrevistas foram desmembradas em duas categorias, concepções (concepções e sensibilização) e práticas (meio ambiente e educação em sala de aula, temas, interdisciplinaridade, dificuldades e suportes).

Para as respostas dos alunos, foram atribuídas as seguintes categorias: definição de Educação Ambiental e meio ambiente; interdisciplinaridade; desenvolvimento de projeto; sustentabilidade; projetos relacionados à Educação Ambiental; envolvimento dos alunos nos projetos: Educação Ambiental na comunidade; e dificuldades para desenvolvimento dos projetos.

\section{RESULTADOS E DISCUSSÕES}

As entrevistas aplicadas aos professores, das instituições de ensino, visaram investigar como a Educação Ambiental está sendo conduzidas pelos professores e instituições de ensino, suas concepções e práticas, bem como as dificuldades enfrentadas quando trabalhadas no contexto da interdisciplinaridade e também o comprometimento das escolas na oferta de suporte e incentivo ao desenvolvimento da Educação Ambiental. Seguem os dados categorizados, conforme respostas dos sujeitos envolvidos.

$\mathrm{Na}$ categoria concepções de Educação Ambiental, os professores entrevistados de ambas as escolas apresentaram discursos ligados diretamente à questão ecológica e a conscientização/sensibilização. Tais concepções resumem-se a cuidados e atitudes que o homem deve ter com o meio ambiente demonstrando assim uma visão naturalista.

Essas concepções estão embasadas nas dimensões naturais da existência e do meio ambiente, porém as dimensões políticas, sociais, culturais e históricas que também fazem parte da Educação Ambiental sequer foram mencionadas nas respostas, apresentando-se somente a concepção de uma Educação Ambiental convencional, desvinculadas das esferas citadas acima e restrita somente à natureza.

As respostas coletadas evidenciam a concepção direcionada a atitudes conservacionistas relacionando a homem/meio. A conscientização é demonstrada através de atitudes básicas com a função de colaborar com a questão ambiental, como foram salientadas questões como o desperdício, a sustentabilidade, à classificação correta dos resíduos, e também a conservação dos ecossistemas. Através destas concepções, contatou-se que a Educação Ambiental tem a função de oferecer subsídios, informações e possibilidades de melhoramento da qualidade de vida da população como resposta simplificada à problemática ambiental.

Os resultados mostram que as maiores partes dos professores entrevistados apresentaram uma visão naturalista e reducionista, vinculando à Educação Ambiental somente questões direcionadas à natureza, num sentido atitudinal e 
conservacionista da natureza. Conforme Carneiro (2008, p. 315), "tal diagnóstico evidencia como necessária e urgente reorientação epistemo-metodológica dos currículos e programas de formação inicial e continuada dos educadores; e o avanço crítico $[\ldots] "$..

$\mathrm{Na}$ categoria práticas, a questão relacionada a temas e conceitos trabalhados em sala de aula, possibilitou a verificação de que as abordagens das temáticas ambientais realizadas pelos professores estão vinculadas aos conhecimentos específicos de suas disciplinas, com a ausência de metodologias criativas ou motivadoras na transmissão de conteúdos.

Dentre as disciplinas, a Geografia é a que mais trabalha a Educação Ambiental, em ambas as escolas, justamente por se tratar de uma ciência que contempla as relações entre a sociedade e a natureza de forma integrada e objetiva levar os educandos a sensibilização como parte integrante do meio ambiente, e que é responsável na maioria dos casos pela modificação do espaço geográfico.

Dentro do contexto da interdisciplinaridade, verificou-se que a Educação Ambiental é apresentada de forma isolada e fragmentada, sendo citadas as disciplinas que já têm a temática ambiental inserida nos currículos, porém existe a consciência de alguns educadores sobre as possibilidades de serem trabalhados os temas transversais em disciplinas não específicas.

As respostas dos professores da segunda escola citada "Filosofia: Todas as disciplinas através de amostras pedagógicas e feiras de conhecimento"'Inglês: Citou as disciplinas que trabalham com as questões relacionadas à EA de forma isolada"."Geografia: Não existem programas na escola, cada educador faz sua parte naturalmente levando os alunos a conscientização." não condizem entre si. Na disciplina de Filosofia, o educador se referiu nas amostras pedagógicas e feiras de conhecimentos realizados por esta instituição de ensino, porém os professores de Inglês e Geografia citaram a inexistência de programas e projetos dentro do ambiente escolar direcionado a Educação Ambiental, demonstrando que o processo ocorre de forma isolada. Sendo assim, de acordo com as respostas, os educadores buscam fazer sua parte no que se refere à conscientização dos educandos e não abrangem toda a comunidade escolar.

As duas instituições pesquisadas deixaram claro que a interdisciplinaridade não ocorre conforme a legislação vigente. O diferencial desta questão é que a primeira escola oferece 0 ensino profissionalizante voltado às práticas agropecuárias, havendo a inserção de disciplinas que envolvem a questão ambiental como requisito do diferenciado currículo da instituição, o que não acontece na segunda escola, a qual obedece ao currículo normal nacional.

Evidencia-se que a temática ambiental é tratada na maioria das vezes, pelas disciplinas afins, o que contribui para a fragmentação e reducionismo dos problemas ambientais. Sendo assim, a perspectiva interdisciplinar se apresenta como um dos princípios essenciais da Educação Ambiental (MORALES, 2009).

Dentre as dificuldades, limites e potencialidades dos professores no desenvolvimento de conteúdos e projetos relacionados à questão ambiental, 
as respostas deixam claro a ausência de projetos de Educação Ambiental. $\mathrm{Na}$ primeira escola, verificou-se a transmissão da responsabilidade para os cursos subsequentes ofertados, vistos que estes são direcionados ao meio ambiente, e a segunda escola, mencionou como limites a carga horária elevada e o número de alunos nas turmas, assim como a elaboração e continuidade permanente dos projetos. Através das respostas, percebe-se que a indisponibilidade de espaço e tempo para a realização de projetos fora do horário de aula, em horários alternativos é um fator limitante para o desenvolvimento da Educação Ambiental.

Sobre os suportes oferecidos pelas escolas, espaços físicos e pedagógicos, os entrevistados da segunda escola se contradizem um com o outro, um deles respondeu que não existem suportes, outro salienta que existem materiais de apoio e recursos didáticos, o espaço físico desta instituição é pequeno comparado com a primeira escola no qual possui uma infraestrutura adequada com uma área ampla, porém não utilizada de maneira satisfatória no desenvolvimento de projetos, de acordo com a maioria dos professores falta comprometimento da equipe pedagógica.

Através das respostas coletadas constatou-se que existem dificuldades de vincular a Educação Ambiental à prática educativa, assim como a sua construção na interdisciplinaridade, segundo os discursos, tais práticas são realizadas individualmente, demonstrando o descomprometimento dos gestores no desenvolvimento da Educação Ambiental através de práticas integradoras.

É necessário ter claro que a Educação Ambiental não deve estar presente no currículo escolar como uma disciplina, porque ela não se destina a isso, mas sim como um tema que permeia todas as relações e atividades escolares, buscando desenvolver-se de maneira interdisciplinar. Se a Educação Ambiental assumir a criticidade de suas proposições em uma perspectiva interdisciplinar, contribuirá para potencializar a transformação da práxis pedagógica (COSTA; LOUREIRO, 2015).

Nesse sentido, faz necessária a formação continuada destes profissionais para que a Educação Ambiental vá além da sensibilização e conscientização, por meio de práticas pedagógicas e ações sustentáveis com perspectiva crítica e emancipatória. Carneiro e Dickmann (2016, p. 233) apresentam a relevância do desenvolvimento da educação ambiental na superação da visão fragmentada de meio ambiente por meio de uma "prática sócio-pedagógica crítica, em vista da sustentabilidade socioambiental", baseada numa "concepção inter-relacional de mundo".

Outros aspectos básicos na formação de professores identificados por Carneiro (2008), que se assemelham a esta pesquisa são: a compreensão de conteúdos ambientais, e da própria educação Ambiental; da prática interdisciplinar e da conexão dos problemas ambientais com o ambiente escolar e comunitário.

Os questionários direcionados aos alunos, através de perguntas investigativas qualitativas foram utilizados para obtenção de dados comprobatórios para a pesquisa, a qual buscou por meio deste instrumento comparar à introdução e 
desenvolvimento da Educação Ambiental em duas escolas com metodologias de ensino diferentes e realidade espacial distintas.

Buscou-se investigar o conhecimento dos alunos de ambas as escolas, quais são as suas concepções sobre a Educação Ambiental, qual a visão sobre projetos e atividades que são desenvolvidos na escola, bem como suas participações e iniciativas para criar e dar continuidade as propostas estabelecidas.

Conforme exposto, os questionários aplicados aos alunos foram tabulados por categorias, possibilitando a produção da seguinte análise sobre a pesquisa. Constam as categorias estabelecidas, as perguntas e respostas dos questionários para investigação e desenvolvimento dos resultados adquiridos.

Em relação ao conceito de Meio Ambiente e Educação Ambiental podemos perceber que os alunos possuem uma visão limitada e convencional. Os conhecimentos ainda encontram-se atrelados apenas à preservação da natureza, podendo interligar reflexos das definições restritas e atividades desenvolvidas em sala de aula.

$\mathrm{Na}$ interdisciplinaridade, os alunos citam determinadas disciplinas que abordam Educação Ambiental como a Geografia, História, Biologia, Química, Artes, Educação Física, Sociologia, Solos e Agroecologia e Produção vegetal. Porém, de acordo com as respostas obtidas, a temática é abordada de maneira superficial ou insatisfatória para as necessidades do momento, resumindo-se em pequenos comentários sobre lixos recicláveis, ou a preservação da natureza, não havendo um envolvimento maior das disciplinas em criar e desenvolver novas práticas e concepções nas escolas, o que levou a constatação da questão através da inexistência de projetos de Educação Ambiental em desenvolvimento ou em planejamento. Sendo assim, impossibilita o aprofundamento e a inter-relação das questões ambientais,

Na categoria Educação Ambiental e comunidade, percebemos de certa forma que as concepções sobre Educação Ambiental como uma corrente integrante entre os ensinamentos de casa com o conhecimento ofertado nas escolas, parte das ideias dos alunos são construídos na escola, mas a educação familiar tem sua importância neste contexto. A Educação Ambiental é transmitida na escola de forma naturalista, não contemplando as diversas áreas que a temática necessita, fazendo com que o educando passe essa forma simplificada de ver os fatos para seus familiares.

Verificamos que existe a sensibilização dos alunos sobre a importância da Educação Ambiental, e a necessidade de projetos de sustentabilidade nas escolas o que não se torna possível com o modelo pedagógico desenvolvido pelas escolas, pois as dificuldades de desenvolver ações nesta área são maiores que a vontade das partes envolvidas.

Mesmo havendo algumas ações restritas a determinadas disciplinas, as atividades desempenhadas não trazem nenhuma nova prática da Educação Ambiental, são projetos saturados pelo tempo que requerem adequações. 
$\mathrm{Na}$ categoria Projetos relacionados à Educação Ambiental os alunos assinalaram as dificuldades encontradas na escola para o desenvolvimento dos projetos, em ambas às escolas, deparam com a falta de comprometimento e envolvimento dos alunos, bem como a falta de incentivos dos professores e da gestão escolar.

Apresentou mais uma vez na pesquisa que apesar da Educação Ambiental ser um assunto da atualidade, que causa preocupações e especulações, e ser uma política pública, encontramos as escolas despreparadas, formando cidadãos inaptos a posturas ambientalmente corretas, sendo que através da dimensão conhecida como Educação Ambiental, quando bem realizada, é possível garantir uma melhora no meio ambiente e na qualidade de vida da população.

Com relação ao envolvimento dos alunos nos projetos, verifica-se que eles têm interesse em participar de projetos, porém são pouco explorados. É de certa forma desanimadora reconhecer que ainda a Educação Ambiental se resume em temas como a "reciclagem de lixo" (resíduos sólidos), mas temos que reconhecer a importância destes projetos para o meio ambiente e também o envolvimento que gera entre os alunos e a escola e respectivamente com a comunidade.

Existe ainda uma grande caminhada a ser percorrida para a construção de projetos inovadores para a Educação Ambiental, mas como ficou expresso nos questionários dos alunos, a falta de interesse por parte dos coordenadores das escolas e até mesmo dos professores em incentivar os próprios alunos na criação de novas ideias, e as dificuldades do percurso só aumentam.

A análise das respostas dos alunos de quais são as maiores dificuldades para o desenvolvimento de projetos de Educação Ambiental entre a escola e a comunidade encontram-se exemplificadas nos Gráficos 1 e 2.

Gráfico 1 - Dificuldades para o desenvolvimento de projetos de Educação Ambiental no Colégio Agrícola Estadual Lysímaco Ferreira da Costa

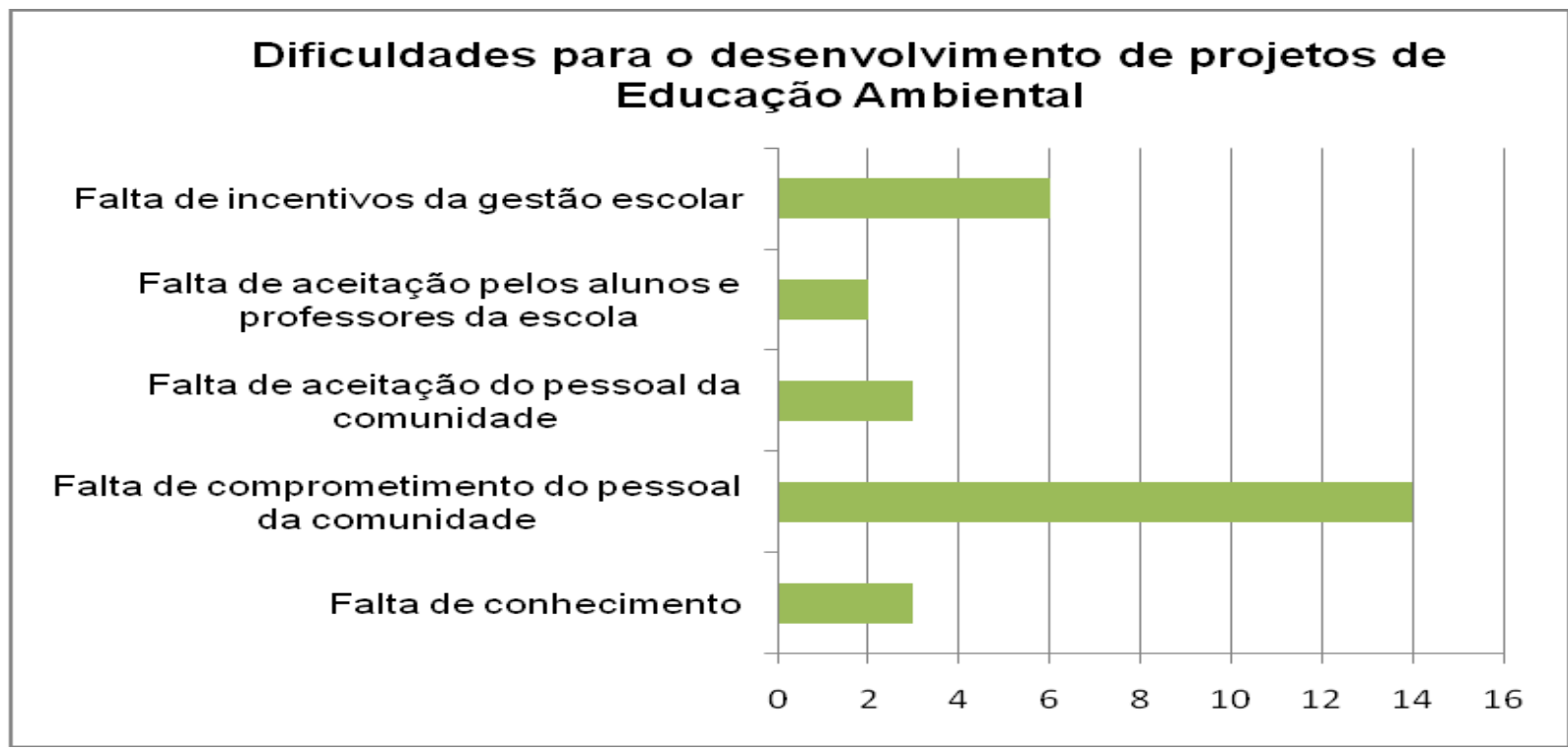

Fonte: Dados da pesquisa (2014) 
Os dados expostos nos Gráficos 1 e 2 demonstram a falta de comprometimento e incentivos da gestão escolar e dos professores como a maior dificuldade para o desenvolvimento de projetos de Educação Ambiental nas escolas. Observamos que as escolas precisam com urgência de ideias e atitudes inovadoras para as salas de aula, não somente para uma melhor compreensão da Educação Ambiental, mas também para uma melhoria do ensino, da qualidade na formação dos alunos, formando cidadãos críticos e habituados a resolver e desenvolver soluções para o seu cotidiano.

Gráfico 2 - Dificuldades para o desenvolvimento de projetos de Educação Ambiental no Colégio Estadual Barão de Antonina.

\section{Dificuldades para o desenvolvimento de projetos de Educação Ambiental}

Falta de incentivos da gestão escolar

Falta de aceitação pelos alunos e professores da escola

Falta de aceitação do pessoal da comunidade

Falta de comprometimento do pessoal da comunidade

Falta de conhecimento

Falta de uma gestão inovadora

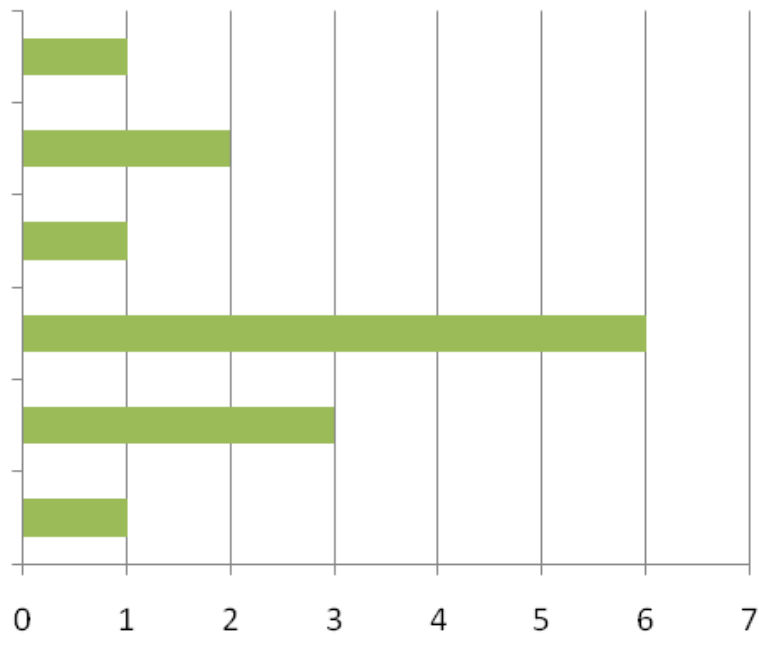

Fonte: Dados da pesquisa (2014)

Observamos na pesquisa, que os alunos possuem uma visão muito superficial em relação à temática ambiental. A primeira escola desenvolve e dá continuidade a alguns projetos incentivados por empresas privadas, porém não observamos o mesmo na segunda escola, demonstrando a falta de comprometimento com a Educação Ambiental na gestão escolar. Tínhamos pressupostos de que o ensino profissionalizante direcionava ações educativas em Educação Ambiental de forma mais eficaz, correspondendo à realidade local e de forma satisfatória para a construção de uma visão holística dos fatos e fenômenos do Planeta. No decorrer da pesquisa constatamos que esse diferencial não é observado da maneira que se esperava, faltando comprometimento com 0 desenvolvimento da Educação Ambiental em ambas as instituições.

A prática escolar é uma dinâmica contínua de ações encadeadas e efeitos cumulativo-transformadores: um recorte diagnóstico da mesma é apenas um momento constatativo e ponto de partida para reflexões projetivas no horizonte do 
hoje para amanhã da educação. Tal conhecimento diagnóstico faz-se mais problemático ao focar os próprios educadores, sendo ainda mais problematizante quanto a processos inovadores, qual seja o caso da educação Ambiental.

As escolas de hoje precisam sim de mais energia humana, profissionais capacitados e prontos para buscar o novo, a escola é habitat da criatividade, da vontade, do desenvolvimento e formação do futuro, buscando reavivar esse espírito do educador que desafia e que desperta o melhor do aluno para o mundo. Por fim, Carneiro (2008) confirma que um recorte diagnóstico da prática escolar é ponto de partida para refletir e problematizar as concepções e práticas docentes quanto aos processos inovadores relativos à Educação Ambiental.

\section{CONSIDERAÇÕES FINAIS}

Os resultados evidenciaram que existem lacunas entre o ensino e a Educação Ambiental a serem preenchidas. As informações obtidas junto aos professores sobre suas concepções e práticas constataram que os mesmos possuem visões tradicionais, onde, suas ações são direcionadas à sensibilização dos alunos e restritas aos conteúdos do currículo não ocorrendo a interdisciplinaridade como orientações da legislação vigente e a inexistência de novas práticas de Educação Ambiental. Na pesquisa com os alunos, onde avaliamos o conhecimento e as ações desenvolvidas dentro e fora do ambiente escolar constatamos que os mesmos possuem uma visão simplificada da Educação Ambiental, sendo necessária e urgente a inserção de medidas socioeducativas que estimulem uma nova metodologia de ensino.

Entendemos que a construção de uma Educação Ambiental efetiva não ocorre de forma rápida, é um processo lento e gradativo que requer capacitação, incentivos, empenho e comprometimento tanto de professores, alunos e da gestão escolar e comunidade.

Consideramos que o processo da inserção da Educação Ambiental requer a elaboração de uma metodologia atrativa e inovadora, que esta não vem de maneira pronta e acabada, necessitando ser construída passo a passo elaborada através da realidade vivenciada pela comunidade escolar na sociedade atual.

Finalmente, ainda existe a necessidade de programas direcionados à formação continuada de professores e da comunidade escolar sendo a chave fundamental para o desenvolvimento da Educação Ambiental, na perspectiva de orientar e formar sujeitos que desenvolvam e se apropriem de atitudes críticas e participativas, frente à complexa realidade ambiental. Além disso, ela tem sido um elemento essencial para se repensar às práticas e teorias nas quais fundamentam as ações educativas, seja nos ambientes formais ou informais da educação, constituindo assim verdadeiras comunidades de aprendizagem. 


\section{REFERÊNCIAS}

BARDIN, L. Análise de conteúdo. São Paulo: Edições 70, 2011.

BRASIL. Resolução n 02, de 15 de junho de 2012. Estabelece as Diretrizes Curriculares Nacionais para a Educação Ambiental. Diário Oficial [da] República Federativa do Brasil, Brasília, DF, v. 149, n. 116, 18 de jun. 2012, Seção 1, p. 70-71.

CARNEIRO, S. M. M. A Educação Ambiental em escolas do ensino fundamental em Curitiba e região metropolitana e a formação de educadores. In: SCHMIDT, M. A.;

CARNEIRO, S. M. M.; DICKMANN, I. Educação Ambiental na escola a partir de Paulo Freire. In: HAGEMEYER, R. C. C.; SÁ, R. A. de; GABARDO, C. V. (Orgs.)

Diálogos epistemológicos e culturais. Curitiba: W\&A Editores, 2016. p. 233-252. (Coleção Pesquisa em Cultura e Escola).

COSTA, C.A.S.; LOUREIRO, C.F.B. Interdisciplinaridade e educação ambiental crítica: questões epistemológicas a partir do materialismo histórico-dialético. Ciênc. Educ., Bauru, v. 21, n. 3, p. 693-708, 2015.

GARCIA, T. M. B.; HORN, G. B. (Orgs.) Diálogos e perspectivas de investigação. ljuí: UNIJUÍ, 2008. p. 311-324. (Coleção Cultura, Escola e Ensino).

MORALES, A. G. A formação do educador ambiental: reflexões, possibilidades e constatações. Ponta Grossa: Editora UEPG, 2009.

OLIVERA, W. C. Contribuições da Geografia para a Educação Ambiental: As Relações entre a Sociedade e a Natureza no distrito Federal. Dissertação de Mestrado. Universidade de Brasília. Departamento de Pós Graduação de Geografia. 2011. Disponível em: < http://repositorio.bce.unb.br/ bitstream/10482/8094/1/ Dissertacao\%2520Washington.pdf > Acesso em: 25 set. 2014.

SAUVÉ, L. Educação Ambiental: possibilidades e limitações. Educação e Pesquisa, São Paulo, v. 31, n. 2, p.317-322, maio/ago. 2005.

SILVA, R. V. A Educação Ambiental e o Ensino de Geografia. In: X ENPEG, Porto Alegre, 2009. Disponível em: < http://www.agb.org.br/XENPEG/ artigos /G T/G T5/t c5\%20(10).pdf > Acesso em: 06/out/2014.

Artigo recebido em: 09/09/2015

Artigo aprovado em: 09/06/2017

Artigo publicado em: 20/12/2017 